\title{
Effect of the calcination temperature on the composition and microstructure of hydroxyapatite derived from human and animal bone
}

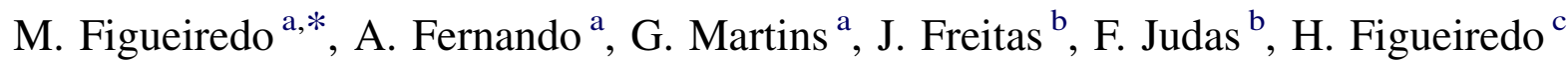 \\ ${ }^{a}$ Chemical Engineering Department, University of Coimbra, R. Sílvio Lima, 3030-790 Coimbra, Portugal \\ ${ }^{\mathrm{b}}$ Orthopaedics Department - Coimbra University Hospital, Pct. Mota Pinto 3000-075 Coimbra, Portugal \\ ${ }^{\mathrm{c}}$ Histology Institute, Medicine Faculty, University of Coimbra, R. Larga, 3004-504 Coimbra, Portugal \\ Received 15 February 2010; received in revised form 28 April 2010; accepted 14 June 2010 \\ Available online 3 August 2010
}

\begin{abstract}
The present work focus the study of cortical bone samples of different origins (human and animal) subjected to different calcination temperatures $\left(600,900\right.$ and $\left.1200{ }^{\circ} \mathrm{C}\right)$ with regard to their chemical and structural properties. For that, not only standard techniques such as thermogravimetric analysis, Fourier transform infrared spectroscopy, X-ray diffraction and scanning electron microscopy were used but also mercury intrusion porosimetry. The latter technique was applied to evaluate the effects of the temperature on the microstructure of the calcined samples regarding porosity and pore size distribution.

Although marked alterations in structure and mineralogy of the bone samples on heating were detected, these alterations were similar for each specimen. At $600{ }^{\circ} \mathrm{C}$ the organic component was removed and a carbonate apatite was obtained. At $900{ }^{\circ} \mathrm{C}$, carbonate was no longer detected and traces of $\mathrm{CaO}$ were found at $1200{ }^{\circ} \mathrm{C}$. Crystallinity degree and crystallite size progressively increased with the calcination temperature, contrary to porosity that strongly decreased at elevated temperatures. In fact, relatively to the control samples, a significant increase in porosity was found in samples calcined at $600{ }^{\circ} \mathrm{C}$ (reaching values around 50\%). At higher temperatures, a dramatic decrease was observed, reaching, at $1200{ }^{\circ} \mathrm{C}$, values comparable to those of the non-calcined bone.
\end{abstract}

(C) 2010 Elsevier Ltd and Techna Group S.r.l. All rights reserved.

Keywords: A. Calcination; B. Porosity; Bone origin hydroxyapatite; Chemical and structural properties

\section{Introduction}

Although autografts are still the most preferred to replace human bone tissue, other alternatives are commonly used to overcome its drawbacks namely the limited supply and the requisite of additional surgery. The alternatives can be allografts, xenografts and synthetic biomaterials [1-5]. Allografts and xenografts, even though currently applied, can introduce risk of rejection and disease transfer $[1-3,6]$. Synthetic hydroxyapatite minimizes these limitations but lacks osteoinductive properties and exhibits poor mechanical properties specially when exposed to wet environments $[4,5,7]$.

Additionally, and despite the advances in preparation technology of synthetic $\mathrm{Ca} / \mathrm{P}$ composites $[2,8,9,10]$, limitations remain in the ability of synthetic bioceramics to duplicate the

\footnotetext{
* Corresponding author. Tel.: +351 239798700; fax: +351 239798703 .

E-mail address: mmf@eq.uc.pt (M. Figueiredo).
}

composition and structure of the mineral component of bone $[9,10,11]$. In fact, natural hydroxyapatite is non-stoichiometric (exhibits a $\mathrm{Ca} / \mathrm{P}$ ratio higher than 1.67) and contains carbonate groups and usually some $\mathrm{Mg}$ and other ions built into its structure. Carbonate is the most abundant substitution in bone mineral (3-8 wt \%) and according to its crystal position, carbonate apatite is designated as "type $\mathrm{A}$ " $\left(\mathrm{OH}^{-}\right)$or "type $\mathrm{B}$ " $\left(\mathrm{PO}_{4}{ }^{3-}\right)$, the latter being the most frequent in human bone $[4,11]$. Although the presence of these ions is very low, they play a vital role in the biological reactions associated with bone metabolism [5,12]. It has been shown that carbonate incorporation tends to decrease the crystallinity and to augment the solubility of hydroxyapatite, enhancing its biodegradation rate $[4,5,10,11]$.

One strategy to improve non-autograft materials while maintaining their advantages regarding their chemical and physical properties is to process natural bone, for example by heat treatment [12-18]. Natural hydroxyapatite obtained in this way has the advantage of inheriting the chemical composition 
and structure of the raw material [12-16], being therefore an alternative solution for numerous applications based on its analogous synthetic products. As compared to allogeneic bone, hydroxyapatite derived from xenogeneic bone (usually of bovine origin) is considered a good option because it is easier to obtain, lower cost and available in unlimited supply [12-17]. The problem that arises with heat treatment at elevated temperatures is that the biogenic composition and structure of bone mineral can change and this may affect the efficacy of this material [17-19].

Although there is some controversy regarding the onset of chemical and structural changes as a consequence of heat treatment, it has been reported that changes in the mineral phase of bone are not significant until degradation and combustion of most of the more labile organic components occurs (around $\left.500{ }^{\circ} \mathrm{C}\right)[13,14,18]$. However, whereas $500-650{ }^{\circ} \mathrm{C}$ is accepted as the temperature range required to completely remove the organic phase of bone [13-18], further heating to $800{ }^{\circ} \mathrm{C}$ may be necessary to eliminate possible pathogenic agents and obtain protein-free samples $[6,20]$. Regarding sample mineralogy, it is generally accepted that heat treatment promotes the crystallinity of bone derived hydroxyapatite and increases the crystallite size [16-19]. Besides, some investigations have shown that heating above $700{ }^{\circ} \mathrm{C}$ causes the formation of new mineral phases (e.g., formation of $\mathrm{CaO}$ for apatites with $\mathrm{Ca} /$ $\mathrm{P}>1.67$ ), depending on the ionic substitution of the starting apatite $[4,14,17,18]$, while other studies do not confirm these observations $[16,19]$. Additionally, on heating, bone experiences extensive changes in microstructure. The porous structure created due to the removal of organic constituents gradually condenses at elevated temperatures and a close interlocking structure is produced $[12,18,21]$. Consequently, the unique microporosity of native bone may be lost and osteocondutivity may thus be reduced. In fact, it has been shown that porosity is a key feature of bone grafts: high open porosity between 100 and $500 \mu \mathrm{m}$ is important for vascularization whereas high microporosity of the material itself may support osteoconductivity [12,22] (recent in vitro and in vivo studies on bioceramics have demonstrated the biological sensitivity to the level of microporosity [11,23-25]).

Despite many studies on heat treatment of bone and hydroxyapatite (natural and synthetic) have been published in the literature, the heating effects on the structural features of bone samples, namely on porosity, have not been quantified. Additionally, systematic comparisons between human and animal derived hydroxyapatite are seldom available [26,27].

The present work focus the study of cortical bone samples of different origins (human, bovine and porcine) subjected to different calcination temperatures, between 600 and $1200{ }^{\circ} \mathrm{C}$, with regard to their influence on the chemical and structural properties. Besides the standard characterization techniques (thermogravimetric analysis, Fourier transform infrared spectroscopy, X-ray diffraction and scanning electron microscopy) a special emphasis was put on the determination of the porosity and pore size distribution of the calcined samples. In addition, a parallelism was drawn between allograft and xenograft samples.

\section{Experimental}

\subsection{Sample preparation}

Hydroxyapatite derived from natural bone (femur diaphysis) of different origins (human, bovine and porcine) was obtained under similar processing conditions. The human bone used in this study was a biologically no longer active femur from a 39year-old male donor, supplied by the bone bank of Coimbra University Hospital (Portugal) [28].

The fresh bones of each specimen were cut into smaller pieces and cleaned well to remove most adhering impurities. Afterwards, the bones were boiled in distilled water for $30 \mathrm{~min}$ for degreasing and easier removal of tissues and bone marrow. This procedure was repeated twice with fresh water. Each diaphysis was then transversely cut into $1.5 \mathrm{~cm}$ thickness slices and the trabecular bone inside was carefully removed to obtain only compact bone samples.

Subsequently, the bone samples were totally degreased through immersion in an alcohol series (ethanol at 70\%, v/v), followed by washing with distilled water. Then they were kept in hydrogen peroxide $(30 \%, \mathrm{v} / \mathrm{v})$ for at least $48 \mathrm{~h}$ and rinsed again. Finally, they were stored in formaldeyde solution $(4 \%, \mathrm{v} /$ v) at $4{ }^{\circ} \mathrm{C}$. Before use, the samples were thoroughly rinsed with distilled water and subsequently dried in a vacuum oven at $50{ }^{\circ} \mathrm{C}$ for 3 days. These dry bone samples represent the controls in this study.

Natural hydroxyapatite was obtained after calcination of the human, bovine and porcine bone samples at 600, 900 and $1200{ }^{\circ} \mathrm{C}$. These temperatures were selected after a preliminary thermogravimetric analysis. A systematic series of test samples was prepared by heating the bone slices in an electric furnace at each temperature for $18 \mathrm{~h}$, under air atmosphere. After calcination, the samples were placed inside a desiccator at room temperature and naturally cooled.

Depending on the characterization techniques, samples were used as blocks (the whole slice/half-slice) or as particles (obtained by crushing the slices into smaller pieces and reducing the fragments to powder form by hand grinding in an agate mortar).

\subsection{Sample characterization}

Simultaneous thermogravimetric analysis (TGA) and Differential Scanning Calorimetry (DSC) of the control samples were carried out using a SDT Q600 equipment (TA Instruments, New Castle, DE, USA). $20 \mathrm{mg}$ of bone sample was heated in an alumina crucible at a rate of $10{ }^{\circ} \mathrm{C} / \mathrm{min}$ from 25 to $1500{ }^{\circ} \mathrm{C}$ under an oxidizing atmosphere using $55 \mathrm{~cm}^{3} / \mathrm{min}$ flux of air. As mentioned, information from thermal analysis was used to select the calcination temperatures more appropriate for the study here reported.

Fourier transform infrared spectroscopy (FTIR) was used to investigate the chemical composition of the controls and of samples calcined at different temperatures. The FTIR spectra were obtained using a Nicolet Magna IR-750 spectrometer (Nicolet, Madison, WI, USA) in the attenuated total reflection 
(ATR) mode. The spectra were registered in the 400$4000 \mathrm{~cm}^{-1}$ region using 64 scans and a spectral resolution of $4 \mathrm{~cm}^{-1}$. Analytical grade type I collagen and hydroxyapatite, purchased from Sigma Aldrich (Portugal), were also used to obtain the corresponding FTIR spectra for comparison with those of control samples.

X-ray Diffraction (XRD) was applied to monitor the phase composition features of the samples before and after calcination at 600,900 and $1200{ }^{\circ} \mathrm{C}$. The samples spectra were collected using a Philips X-PERT diffractometer (Philips, Amsterdam, Netherlands) operating in the Bragg-Brentano configuration with $\mathrm{Co}-\mathrm{K} \alpha \quad(\lambda=1.78897 \AA)$ radiation at a current of $35 \mathrm{~mA}$ and an accelerating voltage of $40 \mathrm{kV}$. Intensity data were collected by the step counting method (step $0.02^{\circ}$ and time $0.5 \mathrm{~s}$ ) in the range $2 \theta=10-100^{\circ}$. Phase identification was performed with reference to the database supplied by the International Centre for Diffraction Data, namely using the Powder Diffraction File no. 84-1998 (hydroxyapatite). The crystallinity degree $\left(X_{\mathrm{c}}\right)$, corresponding to the fraction of crystalline phase present in the examined volume, was evaluated by the relation:

$X_{c}=1-\frac{V_{112 / 300}}{I_{300}}$

where $I_{3} 0_{0}$ is the intensity of ( $\left.\begin{array}{lll}3 & 0 & 0\end{array}\right)$ reflection and $V_{1} 12 / 30_{0}$ is the intensity of the hollow between $\left(\begin{array}{lll}1 & 1 & 2\end{array}\right)$ and $\left(\begin{array}{lll}3 & 0 & 0\end{array}\right)$ reflections [29].

For microstructural analysis, microstrain was assumed to be negligible and all the diffraction peak broadening attributed to crystallite size. Scherrer equation (Eq. (2)) was used to calculate crystallite size $(\tau)$. In this expression, $\lambda$ is the wavelength of the radiation, $\theta$ is the Bragg angle and $B$, the line broadening at half the maximum intensity (FWHM) of the selected peaks in the diffractogram. The $\left(\begin{array}{lll}0 & 0 & 2\end{array}\right)$ reflection of the calcined samples was used for determining the FWHM data.

$\tau=\frac{K \lambda}{B \cos \theta}$

Mercury intrusion porosimetry was employed to analyse the control and calcined bone samples, both in block form. Additionally, some tests were performed in the calcined samples after reduction to particulate form. Porosity and pore size distribution were determined using the AutoPore IV 9500 (Micromeritics Instrument Corp., Norcross, GA, USA). The pressure range varied between $0.5 \mathrm{psi}$ and $30,000 \mathrm{psi}$, which enabled the measurement of pore diameters between 400 and $0.006 \mu \mathrm{m}$, respectively. From the pressure versus intrusion volume, the equipment generates pore size distributions (cumulative and differential curves), using the Washburn equation (Eq. (3)):

$d=\frac{4 \gamma \cos \theta}{P}$

where $d$ is the pore diameter, $P$ is the applied pressure necessary for the mercury to penetrate the sample pores, $\gamma$ is the mercury surface tension $\left(0.48 \mathrm{Nm}^{-1}\right)$ and $\theta$ is the contact angle between mercury and the solid surface $\left(130^{\circ}\right)$. The total porosity was calculated as the ratio of the total intruded volume and the sample bulk volume [30].

Additionally, this technique enabled the calculation of the bulk and skeletal volumes, corresponding to the sample volumes measured at the lowest and the highest intrusion pressures, respectively [30]. It should be stressed that bulk volume includes all open pores (i.e., that have access to the surface) whereas the skeletal volume excludes the pores filled with mercury (i.e., only includes pores smaller than the lower detection limit of the equipment (6 $\mathrm{nm}$ in the present case) and/ or blind pores). Skeletal and true densities follow from dividing the material mass by the respective volume.

Morphological and microstructural analysis of the test samples was carried out using light microscopy and scanning electron microscopy (SEM). Light microscopy was performed using a Nikon Optiphot equipment (Nikon Inc., Melville, NY, USA). The surface of the cross section of the bone samples was polished using increasing grades of silicon carbide paper and finished with both 3 and $0.25 \mu \mathrm{m}$ diamond suspension. SEM observations were carried out in a Philips XL30 microscope (Philips, Amsterdam, Netherlands) operating at $20 \mathrm{kV}$. Prior to analysis, the samples were fractured in a direction perpendicular to the long axis of bone in order to expose their basic organizational units. The test samples were mounted on a double-coated carbon conductive tape and sputter coated with gold.

It should be stressed that in this study, microscopic analysis was mainly used for sample examination and not to perform quantitative measurements. Comparisons between the dimensions of the structural features evaluated directly from the micrographs and those calculated from porosimetry should be made with caution. In fact, although there is generally a good correspondence between the results of the microscopic analysis and those obtained by mercury intrusion, it should be mentioned that the two types of data may differ, especially if pore deviate considerable from cylindrical shape [30]. This is mainly due to differences in the measuring principles of both techniques: the parameter measured by mercury intrusion is the entrance size of the pore whereas in image analysis, the diameter of the pore is based on the cross section $[31,32]$.

\section{Results and discussion}

\subsection{Control samples (non-calcined samples)}

\subsubsection{Thermal analysis}

The thermogravimetric curves of the human, bovine and porcine bone samples are shown in Fig. 1, together with the corresponding heat flow profiles, from 20 to $1400{ }^{\circ} \mathrm{C}$. The most relevant results obtained from the $\mathrm{TG}$ analysis are presented in Table 1.

The thermograms of the control samples show typically three successive steps of weight loss: one below $200{ }^{\circ} \mathrm{C}$, another between 200 and $600{ }^{\circ} \mathrm{C}$, and a third step between 700 and $900{ }^{\circ} \mathrm{C}$. Above this temperature, the weight variation is not significant. The former is attributed to the dehydration of bone (surface and bound water). The second step corresponds to the 


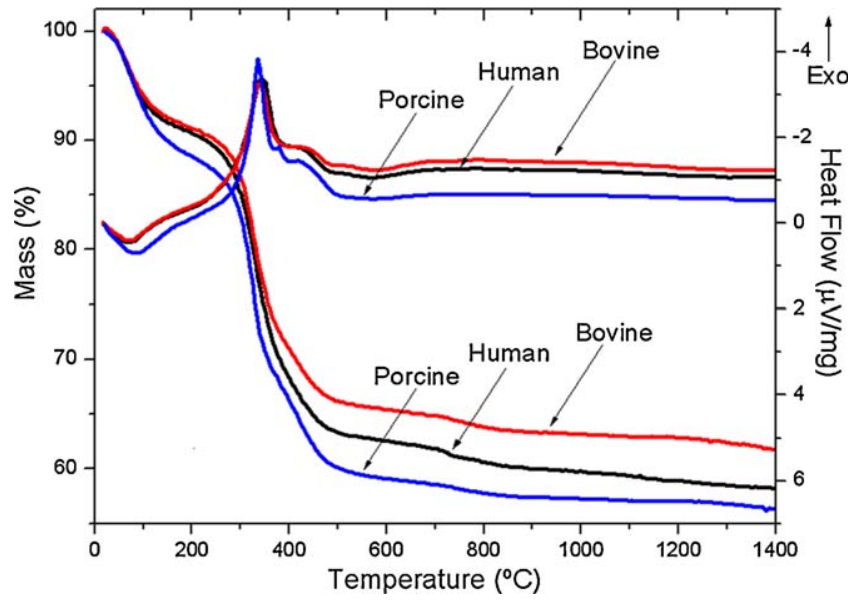

Fig. 1. TG and DSC plots of the control samples (non-calcined human, bovine and porcine bone) in the $25-1400{ }^{\circ} \mathrm{C}$ temperature range.

Table 1

Weight percentage of the main constituents of bone samples of different origins (human, bovine and porcine) estimated from the curves of Fig. 1.

\begin{tabular}{lccc}
\hline & Human & Bovine & Porcine \\
\hline $\mathrm{H}_{2} \mathrm{O}(\mathrm{wt} \%)\left(T<200^{\circ} \mathrm{C}\right)$ & 9.3 & 8.9 & 11.6 \\
Collagen $(\mathrm{wt} \%)\left(200^{\circ} \mathrm{C}<T<600{ }^{\circ} \mathrm{C}\right)$ & 28.1 & 25.7 & 29.4 \\
$\mathrm{Carbonate}^{2} \mathrm{apatite}(\mathrm{wt} \%)^{\mathrm{a}}$ & 62.6 & 65.4 & 59.0 \\
$\mathrm{CO}_{3}{ }^{2-}(\mathrm{wt} \%)^{\mathrm{b}}\left(700^{\circ} \mathrm{C}<T<900{ }^{\circ} \mathrm{C}\right)$ & 5.5 & 4.2 & 3.8 \\
\hline
\end{tabular}

${ }^{\text {a }} \%=100-\left[\left(m_{20}{ }^{\circ} \mathrm{C}-m_{600}{ }^{\circ} \mathrm{C}\right) / m_{20}{ }^{\circ} \mathrm{C}\right] \times 100 \%$.

b $\%=1.36 \times\left[\left(m_{700}{ }^{\circ} \mathrm{C}-m_{900}{ }^{\circ} \mathrm{C}\right) / m_{700}{ }^{\circ} \mathrm{C}\right] \times 100 \%$.

greatest weight loss and is due to the combustion of the organic component of bone (mainly collagen) [14,18,33-35]. The latter step of weight loss, observed at temperatures above $700{ }^{\circ} \mathrm{C}$, is mainly caused by the release of $\mathrm{CO}_{2}$ from the apatite lattice, due to carbonate decomposition [11,14,17,33-35]. The DSC results show, for each bone sample, one endothermic peak at about $90{ }^{\circ} \mathrm{C}$ followed by a strong exothermic peak with maximum near $335^{\circ} \mathrm{C}$ and a shoulder around $420{ }^{\circ} \mathrm{C}$.

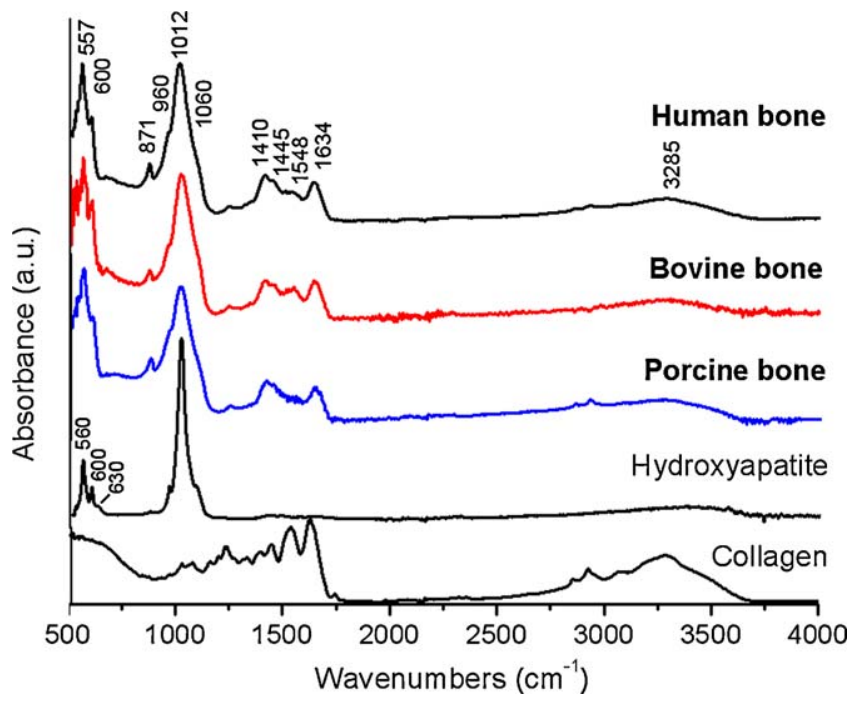

Fig. 2. FTIR spectra of the control samples (human, bovine and porcine bones) and the reference materials (hydroxyapatite and collagen).
Table 1 illustrates that human and bovine samples have similar water content, but slightly inferior to that of porcine bone, and that the organic content differs at most by $4 \%$ among all specimens. The relative amount of carbonate (estimated from the weight loss between 700 and $900{ }^{\circ} \mathrm{C}$, as suggested by the literature $[11,14,17,35]$ ) is also very alike, being the human bone sample that with a slightly higher content.

The above results allowed selecting the set of calcination temperatures-600, 900 and $1200{ }^{\circ} \mathrm{C}$. In fact, besides corresponding to stable chemical compositions (i.e., plateaus
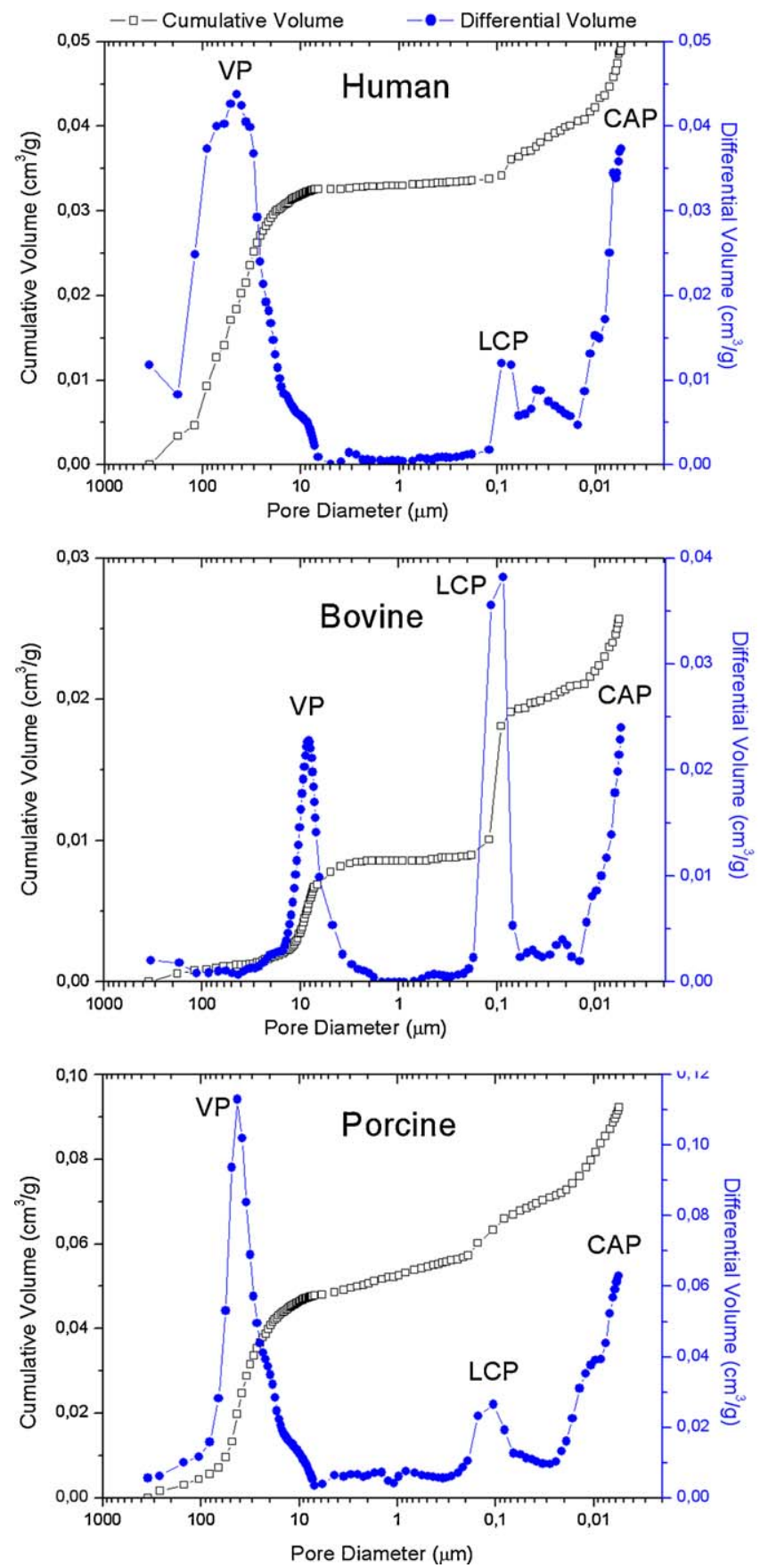

Fig. 3. Cumulative and differential intrusion curves of non-calcined human, bovine and porcine bone samples, measured by mercury porosimetry. VP, vascular porosity; LCP, lacunae-canaliculi porosity; CAP, collagen-apatite porosity. 

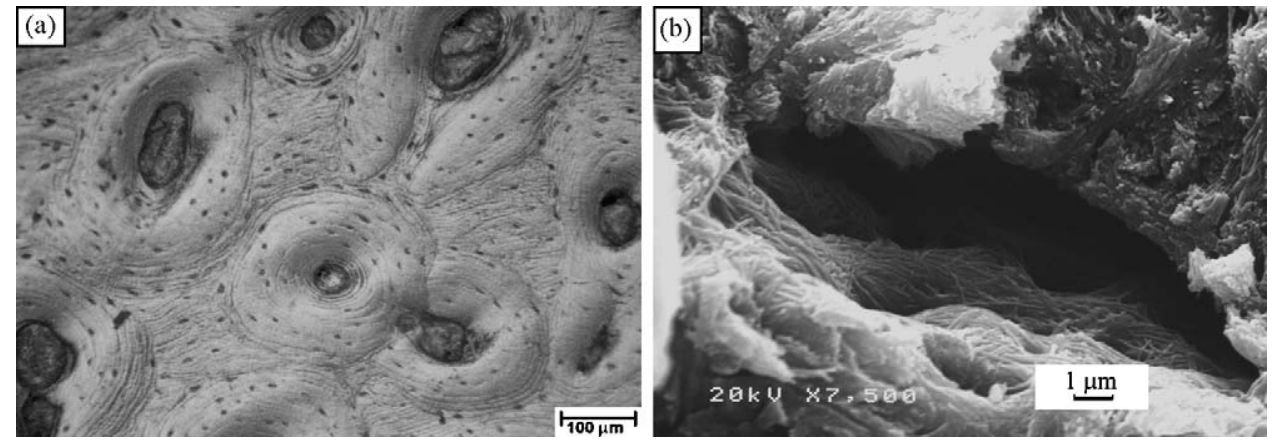

Fig. 4. (a) Light microscopy image of the typical microstructure of cortical bone comprising multiple Havers systems composed of rings of concentric lamellae around each canal and interstitial lamellar bone in between. Numerous lacunae entrapped in the lamellae are also visible. (b) Detailed image of a lacuna, as observed by SEM, shows canaliculi entrances, surrounded by bundles of collagen fibrils.

in TG profiles), at $600{ }^{\circ} \mathrm{C}$ the bone samples are composed of carbonate apatite and at 900 and $1200{ }^{\circ} \mathrm{C}$, mainly of hydroxyapatite.

\subsubsection{FTIR}

Fig. 2 shows the infrared absorption spectra of the control samples, as well as those of hydroxypatite and collagen that were used as reference materials.

The human, bovine and porcine bones present quite similar FTIR spectra, which reflect their identical chemical composition. As expected, each spectrum shows the characteristic peaks of hydroxyapatite (at 557, 600, 960 (shoulder), 1012 and $\sim 1060$ (shoulder) $\mathrm{cm}^{-1}$ due to phosphate vibrations) and collagen $\left(\mathrm{C}=\mathrm{O}\right.$ stretching vibration at $1634 \mathrm{~cm}^{-1} ; \mathrm{N}-\mathrm{H}$ in-plane bending at $1548 \mathrm{~cm}^{-1} ; \mathrm{C}-\mathrm{H}$ and $\mathrm{N}-\mathrm{H}$ stretching modes in the 2800 $3400 \mathrm{~cm}^{-1}$ region) [16,35-37]. It should be noted that the weak band observed in the spectrum of hydroxyapatite at $\sim 630 \mathrm{~cm}^{-1}$ could not be identified in the spectra of the bone samples (Fig. 2). Additionally, the typical bands of carbonate substituting for phosphate site (type B) in the apatite lattice are also observed: peak at $871 \mathrm{~cm}^{-1}$ and double band at 1410/ $1445 \mathrm{~cm}^{-1}$. Type-A carbonate may also be present, but in smaller amounts comparing to type B, since a shoulder around $880 \mathrm{~cm}^{-1}$ is observed in the FTIR spectra of all bone samples $[11,13,14,35-37]$.

\subsubsection{Mercury porosimetry}

All samples analysed exhibit pore size distributions (Fig. 3) which denote the three types of porosity typical of a compact bone: vascular porosity (VP), related to average pore diameters around $50 \mu \mathrm{m}$; lacunae-canaliculi porosity (LCP), corresponding to an average pore size of $0.1 \mu \mathrm{m}$; and collagen-apatite porosity (CAP), with only a few nanometers in diameter. VP corresponds to Harvers and Volkmann canals; LCP, as the name suggests, results from the osteocyte lacunar spaces and the interconnected network of canaliculi that enables the communication within the bone matrix; and CAP corresponds to the empty spaces between collagen fibres and apatite crystals $[38,39]$. The results in terms of total porosity and bulk and skeletal density will be discussed along with the calcined samples.

\subsubsection{SEM}

Fig. 4 presents images from light microscopy (Fig. 4a) and from SEM (Fig. 4b). The former clearly shows some Havers systems, distinctive of cortical bone, constituted of concentric lamellae in which numerous lacunae (small dots) are also visible [40]. The enlarged image of one of these lacunae (Fig. 4b), with a typical oval shape, clearly shows in its interior bundles of collagen fibrils as well as the entrances of the canaliculi [41]. Outside the lacuna it is also evident that the hydroxyapatite crystals are embedded in organic material.

The dimensions of the Havers canals are well within the range of vascular porosity measured by mercury intrusion (Fig. 3). However, regarding the lacunae (whose diameters are between 2 and $7 \mu \mathrm{m}$ ), they are generally measured by porosimetry as canaliculi (around $0.1 \mu \mathrm{m}$ ). This is due to the fact that to reach the lacunae, the mercury has to penetrate through the canaliculi and, as mentioned, the parameter measured by mercury intrusion is the entrance size to the pore (i.e., the canaliculi diameter). This is called the "ink-bottle effect, and as also been reported by other authors $[31,32,38]$.

\subsection{Calcined samples}

\subsubsection{FTIR}

Fig. 5 shows the FTIR spectra in the $500-1800 \mathrm{~cm}^{-1}$ range of the human, bovine and porcine bone samples, before and after thermal treatment at 600,900 and $1200{ }^{\circ} \mathrm{C}$. All absorption bands originated by the collagen, namely those at 1548 and $1634 \mathrm{~cm}^{-1}$ (and also those in the $2800-3400 \mathrm{~cm}^{-1}$ region), disappear after calcination at $600{ }^{\circ} \mathrm{C}$, which suggests that the organic component has been removed from the bone samples. In addition, most of the bands due to the phosphate vibrations of hydroxyapatite have largely increased in intensity after calcination. This behavior has been described by other authors $[17,18]$ as a consequence of the thermal treatment of apatites. In particular, in the $500-700 \mathrm{~cm}^{-1}$ region, there are now three bands in the spectra of the calcined samples (561, 600 and $629 \mathrm{~cm}^{-1}$ ) whereas in the spectra of the original samples only two were clearly discernible $\left(557\right.$ and $600 \mathrm{~cm}^{-1}$ ), i.e. the band at $\sim 630 \mathrm{~cm}^{-1}$ which presents low intensity in the spectrum of hydroxyapatite but is not observed in the original bone samples, is clearly resolved in the spectra of the calcined samples. The 

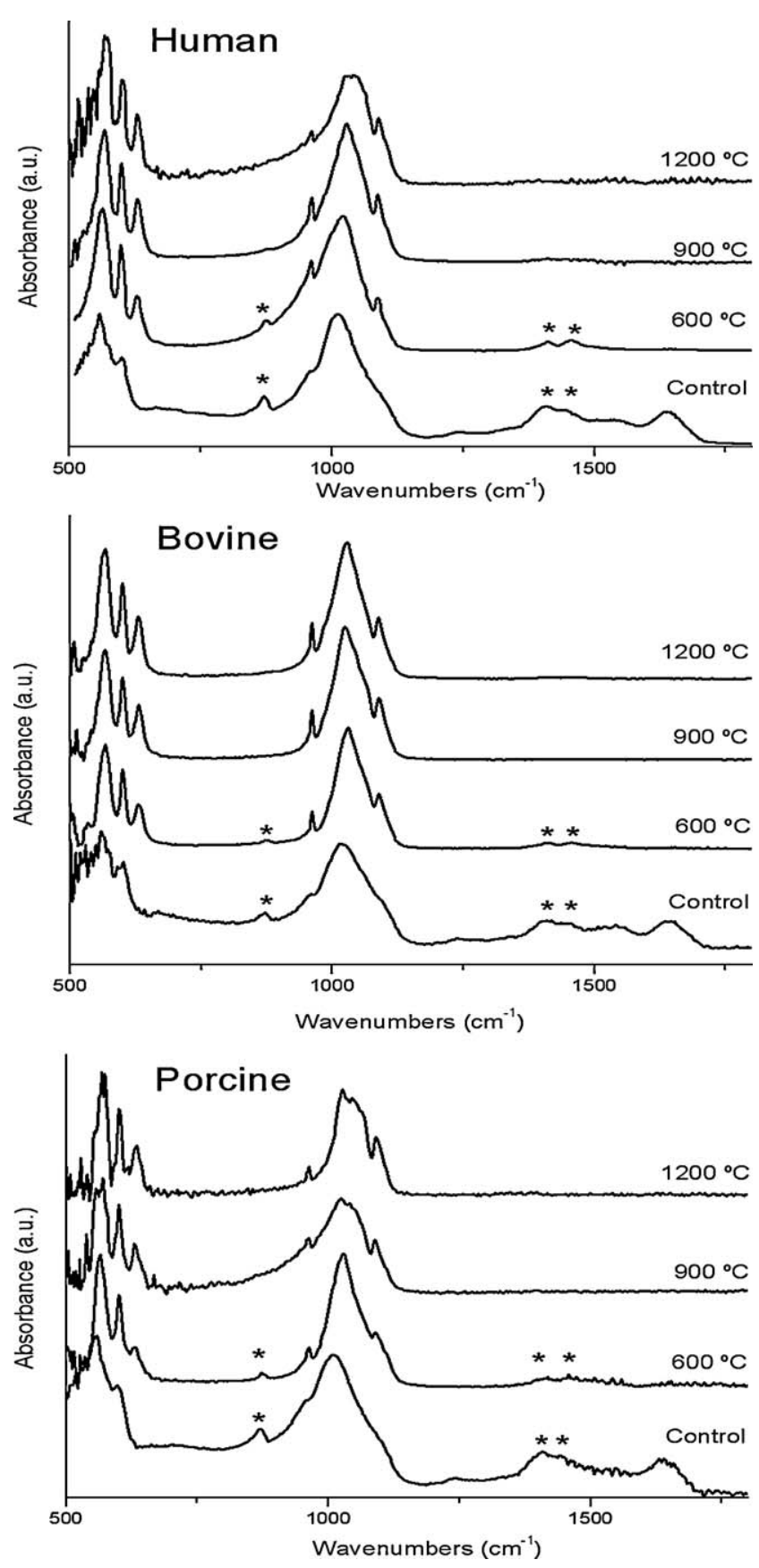

Fig. 5. FTIR spectra of human, bovine and porcine bone samples before and after calcination at 600,900 and $1200{ }^{\circ} \mathrm{C}$. * Bands attributed to lattice carbonate vibrations.

FTIR spectra also show bands of small intensity at 871, 1410 and $1445 \mathrm{~cm}^{-1}$ attributed to lattice carbonate vibrations [11]. Although the relative intensity of these carbonate bands is similar in the various samples spectra, they are more pronounced in the spectrum of the human sample, confirming a higher carbonate content. After calcination at $900{ }^{\circ} \mathrm{C}$, the bands due to carbonate are no longer observed in the spectra of the bone samples. The spectra of the samples calcined at $1200{ }^{\circ} \mathrm{C}$ were similar to those at $900{ }^{\circ} \mathrm{C}$.

These results are fairly consistent with those of thermogravimetric analysis (Table 1) and confirm that the chemical composition of human, bovine and porcine bone samples is quite similar. Moreover, heat treatment at $600{ }^{\circ} \mathrm{C}$ causes the elimination of collagen from bone samples, originating a carbonate apatite, and calcination at higher temperatures (900$1200{ }^{\circ} \mathrm{C}$ ) results in the complete removal of carbonate from the mineral.

\subsection{2. $X R D$}

$\mathrm{X}$-ray diffraction was employed to evaluate the phase purity and the crystallographic structural properties of the mineral component of bone after calcination at the three selected temperatures $\left(600,900\right.$ and $\left.1200{ }^{\circ} \mathrm{C}\right)$. Spectra from the human and bovine samples are depicted in Fig. 6 and quantitative structural parameters derived from XRD analysis for the samples tested are presented in Table 2.

The diffractograms of all calcined samples show only the characteristic pattern of hydroxyapatite (as deduced by comparing to the reference ICDD data file no. 84-1998). These results confirm that the amorphous organic component was removed after calcination at $600{ }^{\circ} \mathrm{C}$.

For $2 \theta$ between $25^{\circ}$ and $45^{\circ}$, the main lattice reflections originate peaks at $30.1,32.8,33.7,37.0,37.5,38.4$ and $39.7^{\circ}$, being respectively assigned to the (llll $\left.0 \begin{array}{lll}0 & 2\end{array}\right),\left(\begin{array}{lll}1 & 0 & 2\end{array}\right),\left(\begin{array}{lll}2 & 1 & 0\end{array}\right)$, (2 111$)$, ( $\left.\begin{array}{lll}1 & 1 & 2\end{array}\right),\left(\begin{array}{lll}3 & 0 & 0\end{array}\right)$ and $\left(\begin{array}{lll}2 & 0 & 2\end{array}\right)$ Miller plans of hydroxyapatite. A few peaks of lower intensity corresponding to hydroxyapatite are also observed. The formation of other mineral phases is not identified in the X-ray diffractograms. Nonetheless, an additional study was performed to investigate the possibility of $\mathrm{CaO}$ formation: the calcined samples were washed with de-carbonated and distilled water and the respective filtrates were chemically analysed [14]. The results revealed that only the samples heated at $1200{ }^{\circ} \mathrm{C}$ contained traces of $\mathrm{CaO}(0.1-0.2 \%)$. Such low percentages justify the non-detection of the respective peaks in the diffractograms.

The XRD results also denote a generalized trend concerning the crystallinity of the calcined samples (Table 2): (i) the relatively broad peaks resultant from heating at $600{ }^{\circ} \mathrm{C}$ reflect a poor crystalline apatite, probably due to the carbonate substitution into the mineral [13,14]; (ii) increasing the temperature to $900{ }^{\circ} \mathrm{C}$ originates more intense and sharp peaks, corresponding to an increase in the mineral crystallinity, which is compatible with crystallite growth and with the elimination of carbonate from the lattice; (iii) further increase of the calcination temperature to $1200{ }^{\circ} \mathrm{C}$ practically has no influence on the crystallinity.

As expected, the observed narrowing of the diffraction peaks is related to changes in the crystallite size that increases with calcination temperature. Additionally, estimates of the crystallite size (Table 2) show that close values are obtained for the various samples at each calcination temperature. These results are consistent with the most significant structural changes of the bone mineral occurring between 600 and $800{ }^{\circ} \mathrm{C}$, as previously reported $[14,42]$.

\subsubsection{Mercury porosimetry}

The results obtained for sample porosity using mercury intrusion are listed in Table 3 for all samples tested, including 

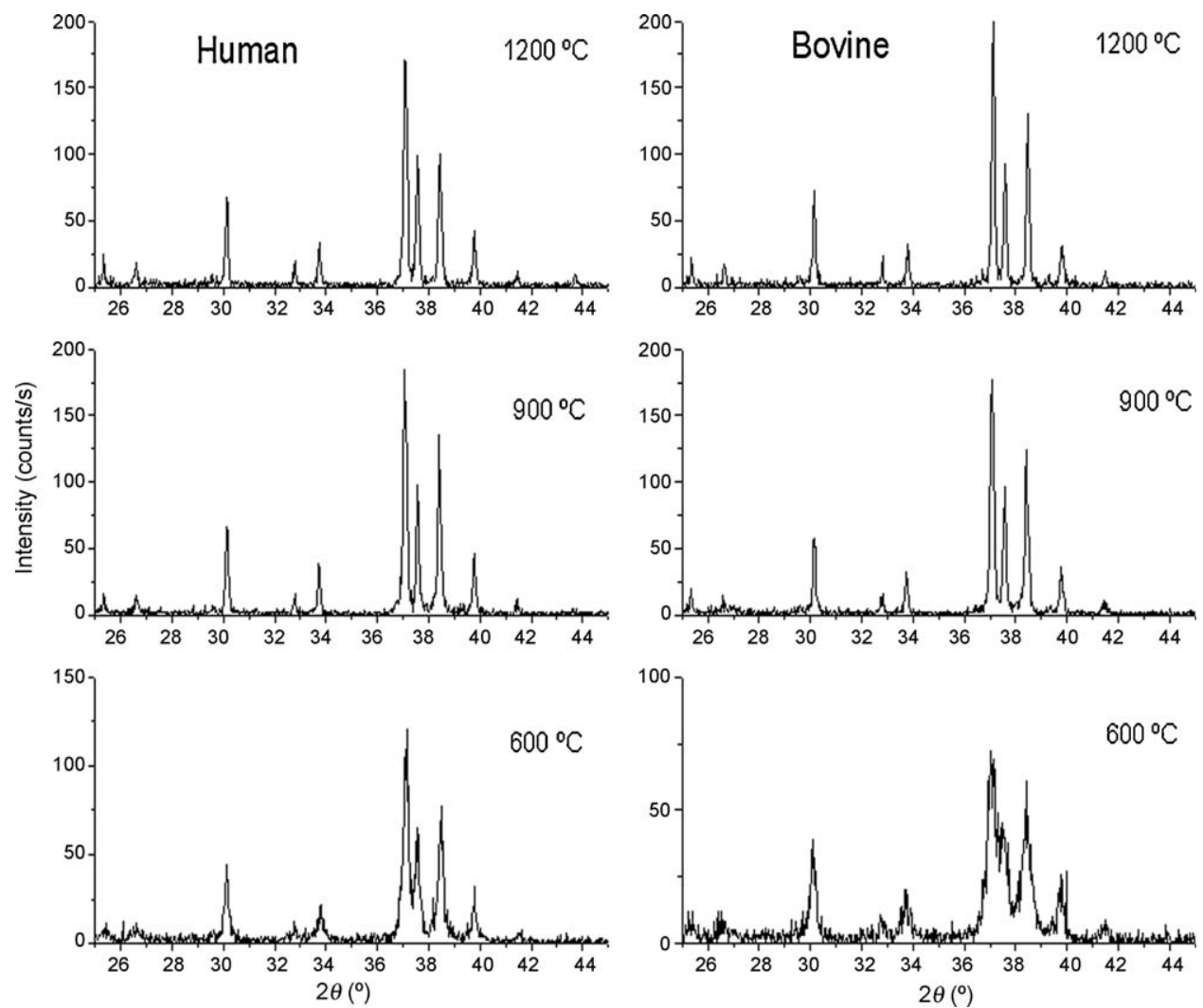

Fig. 6. Diffractograms of human (left) and bovine (right) bone samples calcined at 600,900 and $1200{ }^{\circ} \mathrm{C}$.

the control samples (non-calcined). The reported values correspond to a pore range between $6 \mathrm{~nm}$ and $400 \mu \mathrm{m}$ (the minimum and maximum detection limits of the equipment, respectively). As this table shows, the porosity of non-calcined samples depends on the origin of the sample, varying from around $5 \%$ for bovine bone up to $14 \%$ for porcine bone, having the human bone an intermediate value $(9 \%)$.

These differences are expected since the samples are not directly comparable. Nonetheless they all exhibit a low porosity value, consistent with a compact bone. The effect of calcination at $600{ }^{\circ} \mathrm{C}$ was a significant increase in porosity (which reaches values up to more than 50\%) as a consequence of the releasing of water and burning of organic matter. However, the use of

Table 2

Crystallinity degree $\left(X_{\mathrm{c}}\right)$ and crystallite size $(\tau)$ of bone samples calcined at 600 , 900 and $1200{ }^{\circ} \mathrm{C}$

\begin{tabular}{llll}
\hline Sample & Temperature $\left({ }^{\circ} \mathrm{C}\right)$ & $X_{\mathrm{c}}(\%)^{\mathrm{a}}$ & $\tau(\mathrm{nm})^{\mathrm{b}}$ \\
\hline Human & 600 & 91 & 63 \\
& 900 & 96 & 76 \\
\multirow{3}{*}{ Bovine } & 1200 & 96 & 105 \\
& 600 & 80 & 44 \\
& 900 & 94 & 82 \\
Porcine & 1200 & 95 & 95 \\
& 600 & 85 & 50 \\
& 900 & 95 & 89 \\
& 1200 & 96 & 104 \\
\hline
\end{tabular}

${ }^{\mathrm{a}}$ From Eq. (1).

${ }^{\mathrm{b}}$ From Eq. (2) for the $\left(\begin{array}{lll}0 & 0 & 2\end{array}\right)$ diffraction peak. higher temperatures originates a systematic decrease in porosity, reaching, at $1200{ }^{\circ} \mathrm{C}$, values comparable to those of the control samples. This is in agreement with the increase in crystallinity as well as in crystallite size.

As mentioned before, mercury porosimetry also provides information about sample density: bulk density, defined as the ratio of the sample mass by its bulk volume (solid + all open pores), and skeletal density, calculated from the skeletal

Table 3

Porosity, bulk density and skeletal density of human, bovine and porcine bone samples, before and after calcination at 600,900 and $1200{ }^{\circ} \mathrm{C}$.

\begin{tabular}{|c|c|c|c|c|}
\hline & \multirow[t]{2}{*}{ Non-calcined } & \multicolumn{3}{|c|}{ Temperature $\left({ }^{\circ} \mathrm{C}\right)$} \\
\hline & & 600 & 900 & 1200 \\
\hline \multicolumn{5}{|l|}{ Human } \\
\hline Total porosity (\%) & 9.24 & 46.8 & 37.5 & 11.1 \\
\hline Bulk density $\left(\mathrm{cm}^{3} / \mathrm{g}\right)$ & 1.89 & 1.61 & 1.83 & 2.62 \\
\hline Skeletal density ${ }^{\mathrm{b}}\left(\mathrm{cm}^{3} / \mathrm{g}\right)$ & 2.08 & 3.02 & 2.93 & 2.95 \\
\hline \multicolumn{5}{|l|}{ Bovine } \\
\hline Total porosity (\%) & 5.20 & 54.5 & 31.7 & 12.4 \\
\hline Bulk density ${ }^{\mathrm{a}}\left(\mathrm{cm}^{3} / \mathrm{g}\right)$ & 2.01 & 1.32 & 2.06 & 2.67 \\
\hline Skeletal density ${ }^{\mathrm{b}}\left(\mathrm{cm}^{3} / \mathrm{g}\right)$ & 2.12 & 2.90 & 3.02 & 3.05 \\
\hline \multicolumn{5}{|l|}{ Porcine } \\
\hline Total porosity (\%) & 14.3 & 56.8 & - & 14.7 \\
\hline Bulk density ${ }^{\mathrm{a}}\left(\mathrm{cm}^{3} / \mathrm{g}\right)$ & 1.77 & 1.25 & - & 2.49 \\
\hline Skeletal density ${ }^{\mathrm{b}}\left(\mathrm{cm}^{3} / \mathrm{g}\right)$ & 2.11 & 2.90 & - & 2.91 \\
\hline
\end{tabular}

${ }^{\mathrm{a}}$ Includes all open pores smaller than about $400 \mu \mathrm{m}$ (the upper detection limit of the equipment).

${ }^{\mathrm{b}}$ Only includes pores smaller than $6 \mathrm{~nm}$ (the minimum pore size detectable by the equipment). 

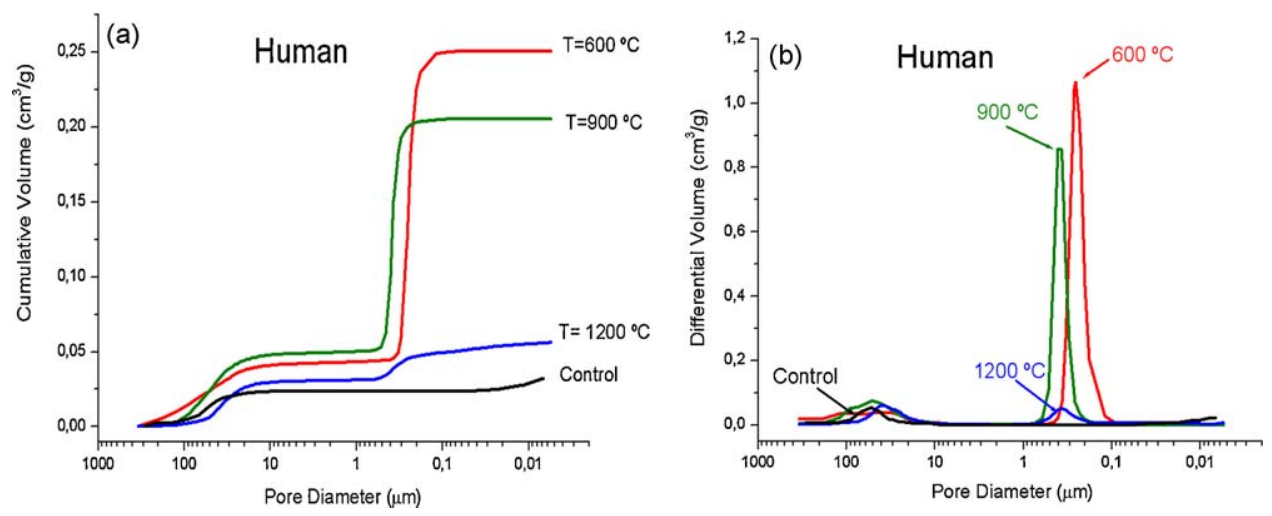

Fig. 7. Cumulative (a) and differential (b) intrusion curves of human bone samples, before and after calcination at 600,900 and $1200{ }^{\circ} \mathrm{C}$, measured by mercury porosimetry.

volume (solid + pores less than the lower limit detected by the porosimeter (i.e., $6 \mathrm{~nm}$ )). According to these definitions, the bulk density values are naturally inferior to those of the skeletal density, being the former dependent upon the sample porosity (reaching the higher values for lower porosities) contrary to the latter that are practically independent of this parameter. Moreover, if the sample does not possess a considerable amount of pores below $6 \mathrm{~nm}$, the skeletal density should be close to the material (solid) absolute density. Thus, it is not surprising that the calcined samples generally exhibit skeletal densities near to $3 \mathrm{~g} / \mathrm{cm}^{3}$, which is close to the theoretical density of hydroxyapatite $\left(3.16 \mathrm{~g} / \mathrm{cm}^{3}\right)$ [43], being those of the control samples about $2 \mathrm{~g} / \mathrm{cm}^{3}$, in agreement with their water and organic content. It should also be emphasized that the value measured for the bulk density of the non-calcined human bone $\left(1.89 \mathrm{~g} / \mathrm{cm}^{3}\right)$ is close to that reported in the literature [22].

Almost as interesting as knowing the total porosity, it is to be able to specify the pore size distribution. Fig. 7 presents the pore size distribution in terms of cumulative and differential curves and clearly illustrate the effect of the calcination temperature on the porosity of the human bone samples. The former curves (Fig. 7a) denote a small intrusion into pores between about 100 and $20 \mu \mathrm{m}$, followed by a plateau and finally another intrusion of mercury into pores smaller than $1 \mu \mathrm{m}$. Although this trend is followed by all cumulative curves, it is apparent that the samples calcined at 600 and $900{ }^{\circ} \mathrm{C}$ correspond to the highest intruded volumes (hence the highest sample porosity) whereas the curve of the sample calcined at $1200{ }^{\circ} \mathrm{C}$ is close to that of the control sample. The pore size ranges are more obvious in the differential curves (Fig. 7b) which clearly exhibit two peaks: a small peak in the $20-120 \mu \mathrm{m}$ region (corresponding to the Havers Canals) and a more prominent peak between 0.1 and $1 \mu \mathrm{m}$ (related to the lacunae/ canaliculi). From the latter, it is also evident that the peak modes (i.e., most frequent diameter) are gradually shifted to the left and are simultaneously less intense as temperatures increases. Furthermore, in comparison to the control sample (Fig. 3), it seems that the nanoporosity has practically vanished. This is obviously related to the micro structural changes resultant from heat treatment. Similar findings were obtained for the animal bone samples (data not shown).
Further tests were performed in the blocks calcined at $600{ }^{\circ} \mathrm{C}$ in order to investigate if this microstructure is kept when the samples are reduced to granular form. For that, the calcined samples were ground by hand in an agate mortar and the resultant particles were again analyzed by mercury intrusion. As an example, the pore size curves of the particles corresponding to bovine sample are depicted in Fig. 8. Again, two intrusion regions are clearly discernible: one between 400 and $10 \mu \mathrm{m}$ and other between 1 and $0.1 \mu \mathrm{m}$. The former peak is much more intense than the corresponding peak of Fig. 7b, because in the case of the packed particles this intrusion corresponds not only to the filling of the Havers Canals but also to the spaces between the particles (interparticle pores). As for the peak corresponding to submicron pores, this is definitely related to the porosity of the individual particles (intraparticle pores) and practically coincides with the equivalent peak of Fig. $7 b$, confirming that the particles maintain the same microstructure evidenced in the blocks. These findings were observed for all samples, being the results listed in Table 4. In comparison to the results of the blocks and as expected, the values obtained for the total porosity are much larger, since the

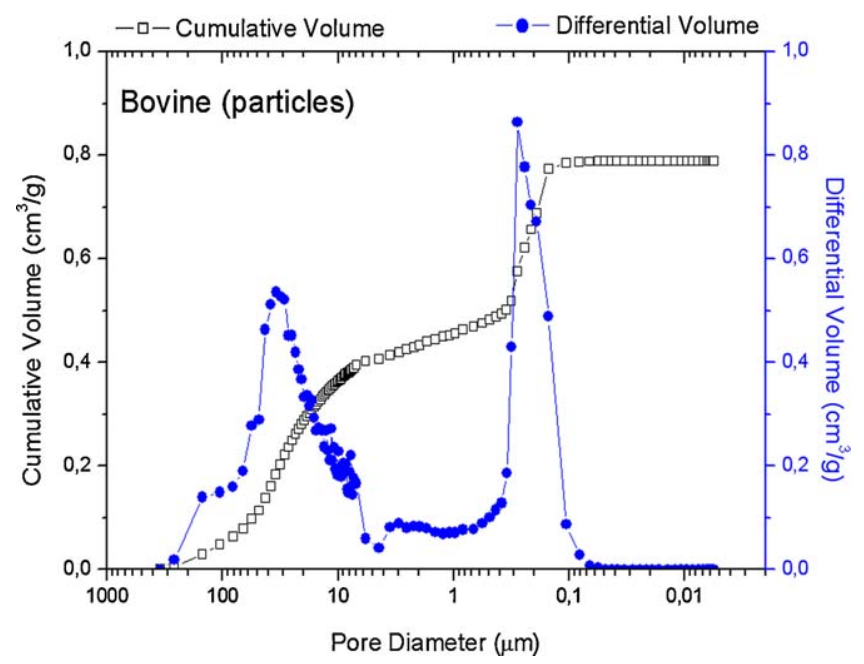

Fig. 8. Cumulative and differential intrusion curves of bovine bone samples calcined at $600{ }^{\circ} \mathrm{C}$ and reduced to particles, measured by mercury porosimetry. 

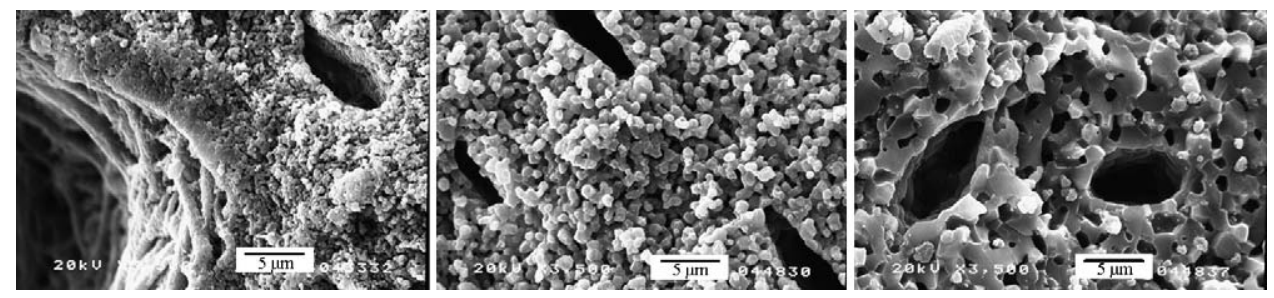

Fig. 9. SEM images of human bone calcined at 600,900 and $1200{ }^{\circ} \mathrm{C}$ (from left to right).
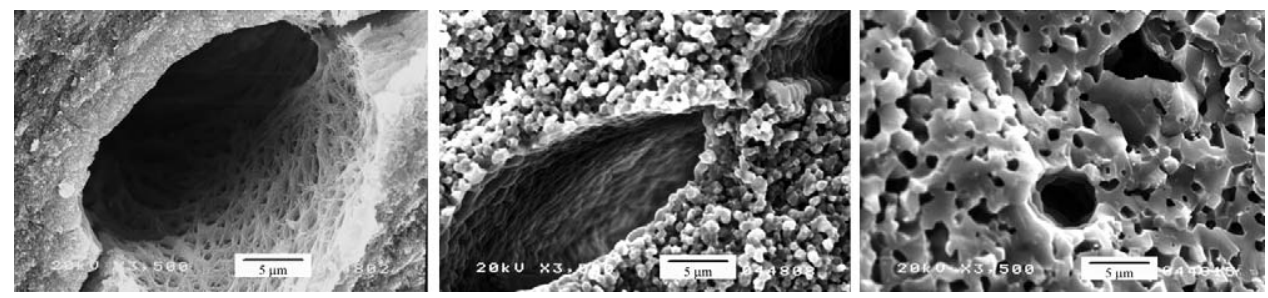

Fig. 10. SEM images of bovine bone calcined at 600,900 and $1200{ }^{\circ} \mathrm{C}$ (from left to right).

amount of interparticle pores has considerably increased. Accordingly, bulk density values were much lower and the skeletal density, surprisingly, slightly decreased. This decrease in the skeletal density needs further investigation.

\subsubsection{SEM}

Representative SEM pictures of the human and bovine bone sample calcined at 600,900 and $1200{ }^{\circ} \mathrm{C}$ are respectively depicted in Figs. 9 and 10. As these images show, the samples' surfaces no longer present the characteristic concentric lamellae around the Havers Canals (like in Fig. 4a) due to the elimination of collagen with heat treatment. Nonetheless, the basic microstructure of cortical bone (Havers Canals and osteocyte lacunar spaces, in particular) was preserved after calcination. Crystal size and morphology, however, display significant changes upon heating.

As for the human bone calcined at $600{ }^{\circ} \mathrm{C}$, Fig. 9 partially shows the interior of a Havers Canal where a record of the formerly existent organic structure can still be observed [44]. Outside the Canal, a lacuna with its typical and well preserved geometry can be noticed. The other images show that as temperature augments the crystal sizes considerably increase. Moreover, at the highest temperature the sintering effect is also obvious. Similar conclusions can be withdrawn from bovine (Fig. 10) and porcine (data not shown) samples.

Table 4

Porosity, bulk density and skeletal density of human, bovine and porcine bone samples calcined at $600{ }^{\circ} \mathrm{C}$ and reduced to particles.

\begin{tabular}{lccc}
\hline & Human & Bovine & Porcine \\
\hline Total porosity $(\%)$ & 73.1 & 69.3 & 68.3 \\
Bulk density $^{\mathrm{a}}\left(\mathrm{cm}^{3} / \mathrm{g}\right)$ & 0.69 & 0.88 & 0.93 \\
Skeletal density $^{\mathrm{b}}\left(\mathrm{cm}^{3} / \mathrm{g}\right)$ & 2.58 & 2.87 & 2.93 \\
\hline
\end{tabular}

\footnotetext{
${ }^{\mathrm{a}}$ Includes all open pores smaller than about $400 \mu \mathrm{m}$ (the upper detection limit of the equipment).

${ }^{\mathrm{b}}$ Only includes pores smaller than $6 \mathrm{~nm}$ (the minimum pore size detectable by the equipment).
}

\section{Conclusions}

The results show that the calcination temperature highly conditions the properties of the bone samples. As expected, higher temperatures lead to more pure forms of hydroxyapatite, with higher crystallinity degrees and larger crystallite sizes and a less porous structure. Furthermore, samples heated to the same temperature exhibit similar characteristics, regardless their origin.

FTIR spectra indicate that the organic constituents are no longer present in the samples calcined at $600{ }^{\circ} \mathrm{C}$, suggesting that this temperature is adequate to obtain protein-free samples. Moreover, these spectra have also revealed that, at this temperature, a carbonate apatite is obtained, being the carbonate removed from the mineral at higher temperatures. Furthermore, no new mineral phases were evident at higher temperatures, in good agreement with the results of thermal analysis and XRD. Nonetheless, traces of $\mathrm{CaO}(0.1-0.2 \%)$ were detected in samples heated at $1200{ }^{\circ} \mathrm{C}$, as revealed by chemical analysis.

Regarding porosity, it was clear that samples calcined at $600{ }^{\circ} \mathrm{C}$ exhibit the highest porosity, around $50 \%$, which, for a compact bone, is quite relevant. However, as the heating temperature increases, the porous structure condenses, sintering at very high temperatures $\left(1200{ }^{\circ} \mathrm{C}\right)$ and originating porosity values comparable to those of the non-calcined samples. Pore size distribution curves show that the most relevant contribution to the total sample porosity is in the region $0.1-1 \mu \mathrm{m}$ (i.e., microporosity). According to the works published in the literature, this microporosity may be essential for inductive bone formation [23-25]. Further tests performed in the samples calcined at $600{ }^{\circ} \mathrm{C}$, reduced to particulate form, confirm that the particles maintain the same microstructure as blocks. Additionally, in the form of particles, samples also exhibit high values of interparticle porosity (with pores around $100 \mu \mathrm{m})$, most convenient for bone remodelling [22]. This is obviously a convenient way of obtaining simultaneously macro and microporosity. 
In conclusion, this work shows that the studied mammalian bone samples calcined at $600{ }^{\circ} \mathrm{C}$ exhibit a most promising chemical composition and structure that could be exploited to provide good alternatives either to synthetic apatite and/or to allogeneic bone.

\section{References}

[1] C.G. Finkemeier, Bone grafting and bone-graft substitutes, J. Bone Joint Surg. Am. 84 (2002) 454-464.

[2] R. Murugan, S. Ramakrishna, Development of nanocomposites for bone grafting, Compos. Sci. Technol. 65 (2005) 2385-2406.

[3] B. Ben-Nissan, Natural bioceramics: from coral to bone and beyond, Curr. Opin. Solid State Mater. Sci. 7 (2003) 283-288.

[4] S.M. Best, A.E. Porter, E.S. Thian, J. Huang, Bioceramics:, Past, present and for the future, J. Eur. Ceram. Soc. 28 (2008) 1319-1327.

[5] F. Barrère, C.A. van Blitterswijk, K. de Groot, Bone regeneration: molecular and cellular interactions with calcium phosphate ceramics, Int. J. Nanomed. 1 (2006) 317-332.

[6] B. Wenz, B. Oesch, M. Horst, Analysis of the risk of transmitting bovine spongiform encephalopathy through bone grafts derived from bovine bone, Biomaterials 22 (2001) 1599-1606.

[7] S. Guizzardi, C. Montanari, S. Migliaccio, R. Strocchi, R. Solmi, D. Martini, A. Ruggeri, Qualitative assessment of natural apatite in vitro and in vivo, J. Biomed. Res. (Appl. Biomater.) 53 (2000) 227234.

[8] M. Gelinsky, P.B. Welzel, P. Simon, A. Bernhardt, U. Kønig, Porous threedimensional scaffolds made of mineralised collagen: preparation and properties of a biomimetic nanocomposite material for tissue engineering of bone, Chem. Eng. J. 137 (2008) 84-96.

[9] T.V. Thamaraiselvi, K. Prabakaran, S. Rajeswari, Synthesis of hydroxyapatite that mimic bone mineralogy, Trends Biomater. Artif. Organs 19 (2006) 81-83.

[10] G.C. Koumoulidis, A.P. Katsoulidis, A.K. Ladavos, P.J. Pomonis, C.C. Trapalis, A.T. Sdoukos, T.C. Vaimakis, Preparation of hydroxyapatite via microemulsion route, J. Colloid Interf. Sci. 259 (2003) 254260.

[11] E. Landi, G. Celotti, G. Logroscino, A. Tampieri, Carbonated hydroxyapatite as bone substitute, J. Eur. Ceram. Soc. 23 (2003) 2931-2937.

[12] S. Joschek, B. Nies, R. Krotz, A. Gopferich, Chemical and physicochemical characterization of porous hydroxyapatite ceramics made of natural bone, Biomaterials 21 (2000) 1645-1658.

[13] R. Murugan, S. Ramakrishna, K.P. Rao, Nanoporous hydroxy-carbonate apatite scaffold made of natural bone, Mater. Lett. 60 (2006) 2844-2847.

[14] K. Haberko, M.M. Bućko, J. Brzezińska-Miecznik, M. Haberko, W. Mozgawa, T. Panz, A. Pyda, J. Zarębski, Natural hydroxyapatite-its behaviour during heat treatment, J. Eur. Ceram. Soc. 26 (2006) 537542.

[15] J. Catanese, J.D.B. Featherstone, T.M. Keaveny, Characterization of the mechanical and ultrastructural properties of heat-treated cortical bone for use as a bone substitute, J. Biomed. Mater. Res. Part A 45 (1990) 327336.

[16] R. Murugan, K.P. Rao, T.S.S. Kumar, Heat-deproteinated xenogeneic bone from slaughterhouse waste: physico-chemical properties, Bull. Mater. Sci. 26 (2003) 523-528.

[17] C.Y. Ooi, M. Hamdi, S. Ramesh, Properties of hydroxyapatite produced by annealing of bovine bone, Ceram. Int. 33 (2007) 1171-1177.

[18] S.E. Etok, E. Valsami-Jones, T.J. Wess, J.C. Hiller, C.A. Maxwell, K.D. Rogers, D.A.C. Manning, M.L. White, E. Lopez-Capel, M.J. Collins, M. Buckley, K.E.H. Penkman, S.L. Woodgate, Structural and chemical changes of thermally treated bone apatite, J. Mater. Sci. 42 (2007) 9807-9816.

[19] J.C. Hillera, T.J.U. Thompson, M.P. Evison, A.T. Chamberlain, T.J. Wess, Bone mineral change during experimental heating: an X-ray scattering investigation, Biomaterials 24 (2003) 5091-5097.
[20] A. Ruksudjarit, K. Pengpat, G. Rujijanagul, T. Tunkasiri, Synthesis and characterization of nanocrystalline hydroxyapatite from natural bovine bone, Curr. Appl. Phys. 8 (2008) 270-272.

[21] T. Accorsi-Mendonça, M.B. Conz, T.C. Barros, L.A. Sena, G.A. Soares, J.M. Granjeiro, Physicochemical characterization of two deproteinized bovine xenografts, Braz. Oral Res. 22 (2008) 5-10.

[22] V. Karageorgiou, D. Kaplan, Porosity of 3D biomaterial scaffols and osteogenesis, Biomaterials 26 (2005) 5474-5491.

[23] X. Li, C.A. van Blitterswijk, Q. Feng, F. Cui, F. Watari, The effect of calcium phosphate microstructure on bone-related cells in vitro, Biomaterials 29 (2008) 3306-3316.

[24] K.A. Hing, B. Annaz, S. Saeed, P.A. Revell, T. Buckland, Microporosity enhances bioactivity of synthetic bone graft substitutes, J. Mater. Sci.: Mater. Med. 16 (2005) 467-475.

[25] M. Motomiya, E.M. Ito, E.M. Takahata, K.E. Kadoya, E.K. Irie, E.A. Minami, Effect of hydroxyapatite porous characteristics on healing outcomes in rabbit posterolateral spinal fusion model, Eur. Spine J. 16 (2007) 2215-2224.

[26] D. Tadic, M. Epple, A thorough physicochemical characterisation of 14 calcium phosphate-based bone substitution materials in comparison to natural bone, Biomaterials 25 (2004) 987-994.

[27] M. Figueiredo, J. Henriques, G. Martins, F. Guerra, F. Judas, H. Figueiredo, Physicochemical characterization of biomaterials commonly used in dentistry as bone substitutes - comparison with human bone, J. Biomed. Mater. Res. 92B (2009) 409-419.

[28] F. Judas, L. Teixeira, A. Proença, Coimbra University Hospitals' Bone and Tissue Bank: twenty-two years of experience, Transplant. Proc. 37 (2005) 2799-2801.

[29] E. Landi, A. Tampieri, G. Celotti, S. Sprio, Densification behavior and mechanisms of synthetic hydroxyapatite, J. Eur. Ceram. Soc. 20 (2000) 2377-2387.

[30] T. Allen, 5th ed., Particle Size Measurement—Surface Area and Pore Size Determination, vol. 2, Kluwer Academic Publishers, Dordrecht, The Netherlands, 1999.

[31] B. Bruckschen, H. Seitz, T.M. Buzug, C. Tille, B. Leukers, S. Irsen, Comparing different porosity measurement methods for characterisation of 3D printed bone replacement scaffolds, Biomed. Tech. (Berl.) 50 (2005) 1609-1610.

[32] G. Turner-Walker, C.M. Nielsen-Marsh, U. Syversen, H. Kars, M.J. Collins, Sub-micron spongiform porosity is the major ultra-structural alteration occurring in archaeological bone, Int. J. Osteoarchaeol. 12 (2002) 407-414.

[33] L.F. Lozano, M.A. Peña-Rico, A. Heredia, Thermal analysis study of human bone, J. Mater. Sci. 38 (2003) 4777-4782.

[34] F. Peters, K. Schwarz, M. Epple, The structure of bone studied with synchrotron X-ray diffraction, X-ray absorption spectroscopy and thermal analysis, Thermochim. Acta 361 (2000) 131-138.

[35] L.D. Mkukuma, J.M.S. Skakle, I.R. Gibson, C.T. Imrie, R.M. Aspden, D.W.L. Hukins, Effect of the proportion of organic material in bone on thermal decomposition of bone mineral: an investigation of a variety of bones from different species using thermogravimetric analysis coupled to mass spectrometry, high-temperature X-ray diffraction, and Fourier transform infrared spectroscopy, Calcif. Tissue Int. 75 (2004) 321-328.

[36] E.P. Paschalis, F. Betts, E. DiCarlo, R. Mendelsohn, A.L. Boskey, FTIR microspectroscopic analysis of normal human cortical and trabecular bone, Calcif. Tissue Int. 61 (1997) 480-486.

[37] I. Rehman, W. Bonfield, Characterization of hydroxyapatite and carbonated apatite by photo acoustic FTIR spectroscopy, J. Mater. Sci.: Mater. Med. 8 (1997) 1-4.

[38] A.V. Cardoso, W.J. Oliveira, G.J.O. Vaz, Cortical bone porosity visualization using mercury porosimetry intrusion data, Revista Matéria 12 (2007) 612-617.

[39] X. Wang, Q. Ni, Determination of cortical bone porosity and pore size distribution using a low field pulsed NMR approach, J. Orthop. Res. 21 (2003) 312-319.

[40] J.Y. Rho, L. Kuhn-Spearing, P. Zioupos, Mechanical properties and the hierarchical structure of bone, Med. Eng. Phys. 20 (1998) 92-102. 
[41] R. Pawlicki, Correlation between the structure of the wall of the bone lacuna and the localization of the osteocyte within this lacuna. Electronmicroscopic studies, Acta Anat. (Basel) 95 (1976) 421-433.

[42] K.D. Rogers, P. Daniels, An X-ray diffraction study of the effects of heat treatment on bone mineral microstructure, Biomaterials 23 (2002) 25772585 .
[43] Mineralogy, Database, General information on Hydroxyapatite, 2010 Online. Available on URL http://webmineral.com/data/Hydroxylapatite. shtml.

[44] J.L. Holden, P.P. Phakey, J.G. Clemen, Scanning electron microscope observations of heat treated human bone, Forensic Sci. Int. 74 (1995) 2945. 